\title{
Editorial
}

\section{About learning and inventing new wheels}

Having just come back from a splendid European Employment Lawyers' Association meeting in the lovely Bratislava and spoken to many national correspondents of this magazine and other lawyers from all over the EU, my belief that we should work together more closely has only strengthened. We face the same problems everywhere and we can learn from each other's mistakes and solutions.

How do we cope with labour market challenges such as migration and ageing? How are we fitting labour platforms and gig work into our national law systems? How can we distinguish employees from independent contractors and do we need another category in the middle? And what about 'new' developments, such as artificial intelligence and the blockchain? Are they a threat to our labour market and our legal thinking? Can algorithms take the place of employers? Do we actually need employers in the long run?

These questions affect us all and we need to provide answers. And this is where, in my view, we can - and should - work together. There's no point in reinventing the wheel in various countries - unless the roads in these countries are fundamentally different. And although they may be true to some extent, I don't believe the differences are vast.

I consider this magazine to be a valuable means of facilitating working together and learning from each other. It is not only enriching to see how other jurisdictions resolve questions about topics that could have arisen anywhere, all the while applying the same legal tools that are available everywhere within the EU, it is also very useful in practice. I frequently refer to EELC when giving advice - and even in court.
In this magazine we can learn about the ever-present topic of disability discrimination, which is the subject of three case reports, but also the highly relevant question on how to ensure that employees are treated equally after a business transfer.

So please go ahead - read, enjoy and learn!

Zef Even, editor 